\title{
BUSCA DE CASOS DE TUBERCULOSE PULMONAR ABREUGRAFIA EM SINTOMATICOS RESPIRATÓRIOS, SEGUIDA DE EXAMES BACTERIOLÓGICOS NOS SUSPEITOS
}

Gilberto Ribeiro Arantes* Antonio Ruffino-Netto **

ARANTES, G. R. \& RufFino-NetTo, A. Busca de casos de tuberculose pulmonar: abreugrafia em sintomáticos respiratórios, seguida de exames bacteriológicos nos suspeitos. Rev. Saúde públ., S. Paulo, 14:185-93, 1980.

RESUMO: Todos os 32.225 adultos matriculados durante um ano no Centro de Saúde de Ribeirão Preto, Estado de São Paulo, Brasil, foram interrogados quanto d̀ presença de sintomas respiratórios e abreugrafados. Aos sintomáticos foi dada orientação para a colheita de escarro com vistas a baciloscopia e da cultura para bacilo da tuberculose. O exame abreugráfico selecionou 230 portadores de sombras anormais $(0,75 \%)$ entre os 30.846 assintomáticos e 328 $(23,8 \%)$ entre os 1.379 sintomáticos. Dos 90 doentes descobertos, 57 eram sintomóticos baciliferos, 28 sintomáticos não-baciliferos e 5 assintomáticos. Se a busca de casos tivesse sido realizada somente nos sintomáticos respiratórios, sem utilizaçấo da abreugrafia, 33 doentes deixariam de ser descobertos. Por sua vez a pesquisa apenas em sintomáticos portadores de sombras anormais teria economizado 30.846 abreugrafias deixando de descobrir só 5 casos assintomáticos, ou seja, clinicamente inexpressivos. Foi qualificado o potencial epidemiológ co desse tipo de caso concluindo-se que o mesmo é desprezivel.

UNITERMos: Tuberculose. Tuberculose pulmonar. Escarro, exame bacteriológico. Fluoroscopia.

\section{INTRODUÇÃO}

O diagnóstico da tuberculose pulmonar é tarefa compreendida no âmbito das atribuições do médico, tendo como objet.vo maior o alivio do sofrimento individual. A ousca de casos na população é atribuição de um sistema de saúde, do qual o médico é apenas um componente, sendo o seu objetivo principal localizar aqueles pacientes que constituem risco para a comunidade, a fim de tratá-los adequadamente e com isso romper a cadeia de transmissão.

Trata-se pois de empreendimento complexo que requer a contribuição de variados recursos humanos e materiais, acompanhado de medidas destinadas à mobilização da própria comunidade, para que as fontes de infecção sejam localizadas, se possivel,

* Do Departamento de Epilemiologia da Faculdade de Saúde Pública da USP - Av. Dr. Arnaldo, 715 - 01255 - São Paulo, SP - Brasil.

* Do Departamento de Medicina Social da Fasuldade de Medicina de Ribeirão Preto da USP - "Campus" de Ribeirão Preto - 14100 - Ribeirão Preto, SP - Brasil. 
ARANTES, G. R. \& RUFFINO-NETTO, A. Busca de casos de tuberculose pulmonar: abreugrafia em sintomáticos respiratórios, seguida de exames bacteriológicos nos suspeitos. Rev. Saúde puibl., S. Paulo, 14:185-93, 1980.

T A B E L A 1

Distribuição dos sintomáticos respiratórios e dos nāo-sintomáticos segundo o resultado abreugráfico inicial.

\begin{tabular}{|c|c|c|c|}
\hline \multirow{2}{*}{$\begin{array}{l}\text { Resultado da } \\
\text { abreugrafia }\end{array}$} & Sintomas & respiratórios & \multirow{2}{*}{ Total } \\
\hline & Ausentes & Presentes & \\
\hline Processo não tuberculoso & 106 & 138 & 244 \\
\hline Lesão residual & 45 & 32 & 77 \\
\hline Derrame pleural & 8 & 14 & 22 \\
\hline Tuberculose mínima & 52 & 67 & 119 \\
\hline Tuberculose moderadamente avançada & 14 & 25 & 39 \\
\hline Tuberculose muito avançada & $\mathbf{5}$ & 52 & 57 \\
\hline Sub-total & $\begin{array}{c}230 \\
(0,75 \%)\end{array}$ & $\begin{array}{c}328 \\
(23,8 \%)\end{array}$ & $\begin{array}{l}558^{*} \\
(1,7 \%)\end{array}$ \\
\hline Normal & 30.616 & 1.051 & 31.667 \\
\hline Total & $\begin{array}{l}30.846 \\
(100,0 \%)\end{array}$ & $\begin{array}{l}1.379 \\
(100,0 \%)\end{array}$ & $\begin{array}{l}32.225 \\
(100,0 \%)\end{array}$ \\
\hline
\end{tabular}

TA B E L A 2

Distribuição dos casos de tuberculose pulmonar, baciliferos e não-baciliferos, segundo a classificação radiológica final.

\begin{tabular}{|c|c|c|c|c|c|}
\hline \multirow{2}{*}{$\begin{array}{l}\text { Classificação } \\
\text { radiológica }\end{array}$} & \multirow{2}{*}{$\begin{array}{l}\text { Pacientes } \\
\begin{array}{c}\text { Baciloscopia } \\
\text { positiva }\end{array}\end{array}$} & \multirow{2}{*}{$\frac{\text { baciliferos }}{\begin{array}{c}\text { so cultura } \\
\text { positiva }\end{array}}$} & \multicolumn{2}{|c|}{ Pacientes não-baciliferos } & \multirow[b]{2}{*}{ Total } \\
\hline & & & $\begin{array}{l}\text { Com sintomas } \\
\text { respiratórios }\end{array}$ & $\begin{array}{l}\text { Sem sintomas } \\
\text { respiratórios }\end{array}$ & \\
\hline Tuberculose minima & 一 & 10 & 14 & 4 & 28 \\
\hline $\begin{array}{l}\text { Tuberculose moterada- } \\
\text { mente avançada }\end{array}$ & 9 & 7 & 10 & 1 & 27 \\
\hline $\begin{array}{l}\text { Tuberculose muito } \\
\text { avançada }\end{array}$ & 28 & 3 & 2 & - & 33 \\
\hline $\begin{array}{l}\text { Derrame pleural }+ \\
\text { tuberculose mínima }\end{array}$ & - & - & 2 & - & 2 \\
\hline Total & $37(41,1 \%)$ & $20(22,2 \%)$ & $28(31,1 \%)$ & $5(5,6 \%)$ & $90(100,0 \%)$ \\
\hline
\end{tabular}


ARANTES, G. R. \& RUFFINO-NETTO, A. Busc a de casos de tuberculose pulmonar: abreugrafia em sintomáticos respiratórios, seguida de exames bacteriológicos nos suspeitos. Rev. Saude públ., S. Paulo, 14:185-93, 1980.

antes que tenham cumprido integralmente o seu papel disseminador. Nem todos os pacientes se dão conta dos seus sintomas e quando conscientes dos mesmos nem sempre se preocupam ${ }^{5}$; e, quando preocupados, freqüentemente demoram para comparecer aos serviços, nem sempre disponiveis $\mathrm{e}$ accessiveis.

A busca de casos baseada no cadastramento abreugráfico indiscriminado não permite a necessária extensão de cobertura devido aos elevados custos do investimento ${ }^{1}$. Além disso, é um procedimento prejudicial porque submete desnecessariamente milhares de pessoas aos efeitos nocivos das radiações ionizantes ${ }^{6}$; e, também, inconveniente porque contribui sobremaneira para que inúmeras pessoas não-tuberculosas sejam indevidamente submetidas à quimioterapia especifica. Em contra-partida a busca de casos através do exame bacteriológico do escarro de pessoas portadoras de sintomas respiratórios, embora pertinente do ponto de vista epidemiológico, não leva em conta os aspectos médico-sociais do problema.

Em trabalho anteriormente publicado foi observado que o cadastramento bacteriológico pode ter os seus custos substancialmente diminuidos se forem submetidos a esse processo apenas os indivíduos com sintomas respiratórios portadores de sombras suspeitas à abreugrafia ${ }^{3}$.

Neste artigo pretende-se mostrar que essa prática, além de vantajosa do ponto de vista econômico, é também eticamente mais correta por incluir a doença sintomática não bacilifera, causa de sofrimentos para os pacientes e seus familiares.

\section{MATERIAL E METODOS}

A população de estudo foi constituída por pessoas maiores de 15 anos residentes em Ribeirão Preto, Estado de São Paulo, atendidas no Centro de Saúde polivalente desta cidade, no periodo de maio de 1973 até abril de 1974. Esta população, constituída por consultantes e postulantes de certificados de saúde, na ocasião da matrícula foi interrogada quanto à presença $e$ duração de tosse e expectoração; em seguida cada indivíduo foi abreugrafado, independentemente do teor da resposta; os sintomáticos foram orientados para a colheita de escarro o qual foi submetido simultaneamente à baciloscopia e à cultura para bacilo da tuberculose. Os anormais ao exame abreugráfico, cujo exame bacteriológico inicial toi negativo, passaram por avaliação clínica e complementar até a elucidação do diagnóstico. Detalhes a respeito do material e da metodologia empregada neste estudo podem ser obtidos em outra publicação?.

\section{RESULTADOS}

Dos 154.000 habitantes com 15 e mais anos de idade, 32.225 (21\%) foram matriculados, interrogados e abreugrafados, resultando em $1.379(4,3 \%)$ sintomáticos respiratórios e $558(1,7 \%)$ abreugraficamente anormais. Na Tabela 1 é apresentada a distribuição dos sintomáticos e não sintomáticos segundo a classificação abreugráfica inicial. Na Tabela 2 pode-se observar a proporção de doentes baciliferos $\mathrm{E}$ não-bacilíferos (com e sem sintomas respiratórios) segundo as diferentes formas radiológicas finais. Para facilitar a análise os dados das Tabelas 1 e 2 foram sintetizados de forma dicotômica na Figura.

\section{DISCUSSÃO E CONCLUSÓES}

Existindo serviços capacitados para o atendimento às pessoas portadoras de sintomas respiratórios, cedo ou tarde uma grande parte dos casos baciliferos será encaminhada a esses serviços 4,7,13. Não se pode negar porém que um significativo número deles será descoberto e tratado algum tempo depois de ter espalhado a infecção, tempo esse tanto maior quanto menor a motivação da comunidade e mais 
ARANTES, G. R. \& RUFFINO-NETTO, A. Busca de casos de tuberculose pulmonar: abreugrafia em sintomáticos respiratórios, seguida de exames bacteriológicos nos suspeitos. Rev. Saúde públ., S. Paulo, 14:185-93, 1980.

raros, distantes ou desacreditados os serviços disponiveis. No material estudado $50 \%$ dos casos bacilíferos apresentaram-se com lesões radiologicamente muito avançadas e $65 \%$ com escarro positivo ao exame direto.

O cadastramento completo da populaçáo estudada (abreugrafia em todos os individuos, seguida de exames bacteriológicos e avaliação clínico-radiológica e laboratorial) propiciou a descoberta de todos os casos nela contidos - sintomáticos baciliferos e não-baciliferos e pacientes ainda assinto- máticos. Os dados contidos nas Tabelas 1 e 2 e sintetizados na Figura, revelam alguns aspectos importantes: a incidência de alteraçōes abreugráficas entre os assintomáticos foi diminuta - ou seja, de apenas $0,75 \%$ - ao passo que entre os sintomáticos a taxa observada foi substancial, atingindo a quase $25 \%$; a proporção de casos sintomáticos não-baciliferos foi de $31 \%$ ao passo que os doentes assintomáticos não passaram de $5,6 \%$.

Se a busca abreugráfica tivesse sido realizada apenas entre os sintomáticos respirató-

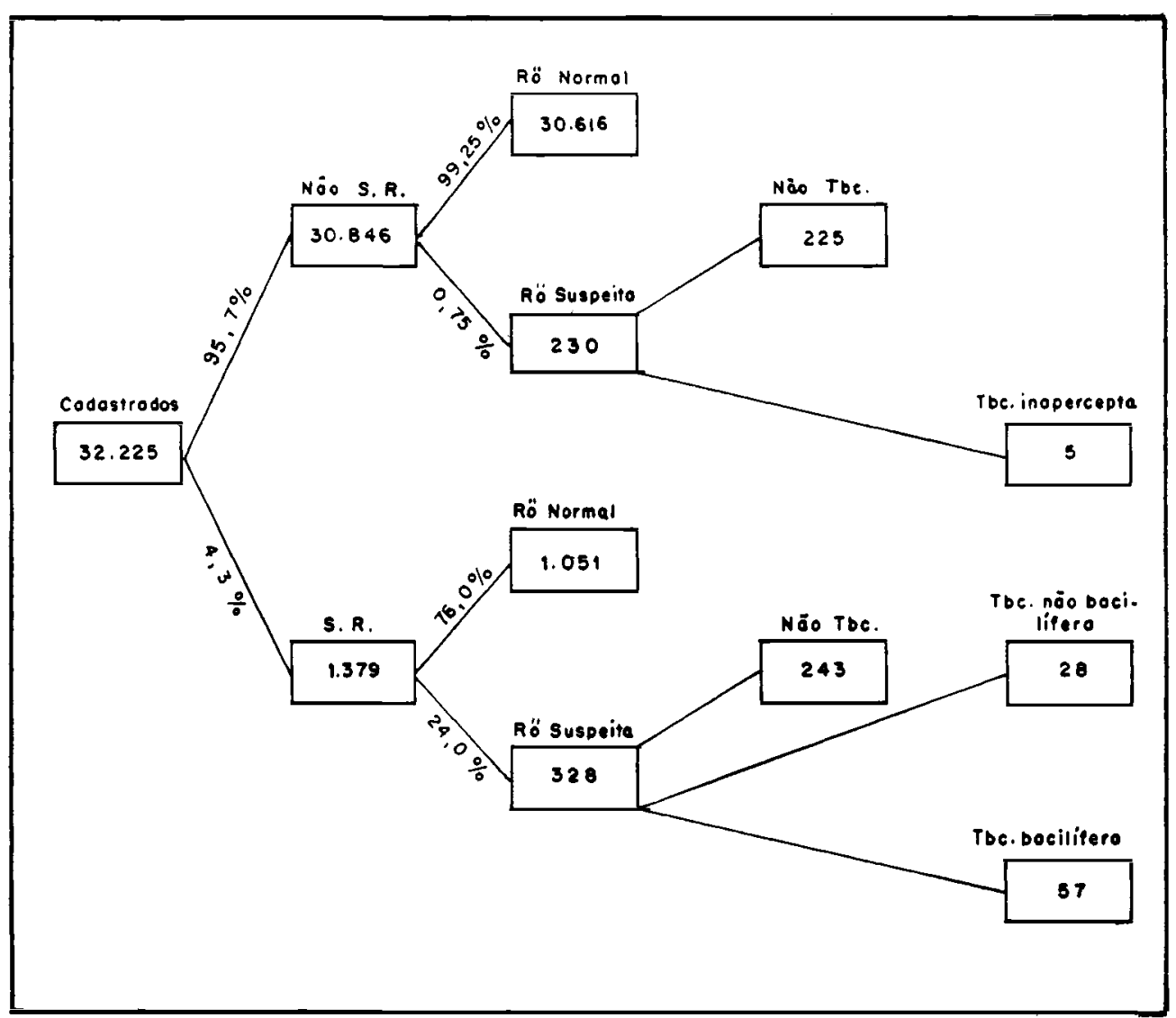

Figura - Perfil da demanda de um Centro de Saude (adultos) face aos métodos de busca de casos de tuberculose pulmonar. $\mathrm{SR}=$ Sintomáticos respiratórios. $\mathrm{Rö}=$ abreugrafia. 
ARANTES, G. R. \& RUFFINO-NETTO, A. Busc a de casos de tuberculose pulmonar: abreugrafia em sintomáticos respiratórios, seguida de exames bacteriológicos nos suspeitos. Rev. Saúde públ., S. Paulo, 14:185-93, 1980.

rios, o número de indivíduos abreugrafados teria diminuído de 32.225 para 1.379 e o de abreugrafias suspeitas, de 558 para 328 , com evidente economia de tempo, recursos materiais e mão-de-obra especializada. Em contra-partida 5 doentes deixariam de ser descobertos, 4 dos quais com lesões mínimas, clinicamente inexpressivos enquanto assintomáticos. O potencial epidemiológico desses casos foi bem estudado. Na Inglaterra a evolução para doença bacilifera, sem tratamento, foi de $30,4 \%$ ao cabo de 5 anos ${ }^{14}$; na Escócia a taxa de deterioração bacilífera em 5 anos foi igual a $6,3 \% 12$; na India, em um estudo a deterioração alcançou $32 \%$ em 6 anos ${ }^{10}$ ao passo que em outro não passou de $12 \%$ em 5 anos 8. Acrescente-se que a busca de casos não é um fim em si mesma, sendo o tratamento e cura dos doentes descobertos seu objetivo maior; ora, uma boa parcela das pessoas nessa categoria recusa o tratamento ou não o segue com a regularidade neces-

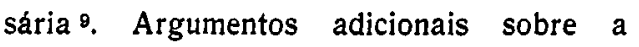
irrelevância desses casos, do ponto de vista epidemiológico, poderão ser apreciados na demonstração apresentada em anexo ao final deste trabalho.

Por sua vez a busca de casos baseada apenas no exame bacteriológico dos sintomáticos respiratórios, sem participação da abreugrafia, teria deixado de descobrir, além daqueles 5 casos assintomáticos, mais 28 pacientes $(31 \%)$ epidemiologicamente não prioritários, porém clinicamente doentes e por isso merecedores de atenção.

A questão da escolha entre este ou aquele método de busca de casos de tuber- culose pulmonar não deve se ater apenas ao confronto entre os méritos relativos de cada processo; na verdade é preciso estabelecer prioridades, das quais a primeira, inquestionavelmente, é constituida pelos doentes baciliferos e a segunda pelos pacientes sintomáticos ainda não-baciliferos, dos quais certamente alguns virão a sê-lo, ficando de fora, pelas razões expostas, os pacientes assintomáticos. $O$ posicionamento face ao assunto deve ser realizado em consonância com a magnitude do problema tuberculose na área, disponibilidade tecnológica e custos. Para a área em pauta, na falta de dados diretos, é possivel se estimar, apenas para fins de raciocinio, que em cada cem mil habitantes ocorram anualmente 60 casos de tuberculose positivos à baciloscopia 11,16, sendo 30 casos positivos apenas à cultura 11 e 24 bacteriologicamente negativos *, ou seja, uma incidência total ao redor de 114 casos. Quanto à tecnologia, dispõe-se também de equipamentos abreugráfico-radiológicos; e o custo por caso descoberto e tratado foi menor com a busca em sintomáticos respiratórios selecionados pela abreugrafia do que com a realizada em todos os sintomáticos respiratórios ${ }^{3}$. Isto posto, impõe-se a pesquisa de pessoas com sintomas respiratórios na população, os quais, nas localidades equipadas serão abreugrafados, submetendo-se ao exame bacteriológico tão somente os escarros dos indivíduos suspeitos. Assim, em vez de se contrapor um processo ao outro, estaríamos somando os dois, com evidentes benefícios para a população, além da economia, encerrando de vez a interminável polêmica que vem se desenrolando à respeito.

* Adaptação do parametro contido no Roteiro de programação de unidade de saúde, da Divisão Nacional de Pneumologia Sanitária, 1977. 
ARANTES, G. R. \& RUFFINO-NETTO, A. Busoa de casos de tuberculose pulmonar: abreugrafia em sintomáticos respiratóros, seguida de exames bacteriológicos nos suspeitos. Rev. Saride públ., S. Paulo, 14:185-93, 1980.

ARANTES, G. R. \& RufFino-NetTo, A. [Case-finding for pulmonary tuberculosis through photofluorography and sputum examination of symptomatic persons] Rev. Saude públ., S. Paulo, 14:185-93, 1980.

ABSTRACT: To determine the best pattern for the use of radiology in tuberculosis case-finding, all registrants aged 15 and over at the Public Health Center of Ribeirão Preto, SP (Brazil) were questioned for respiratory symptoms and had a $70 \mathrm{~mm}$ chest photofluorogram taken. This program was carried on for a year. Each symptomatic sputum specimen was examined through microscopy and culture. Each registrant with an abnormal $X$-ray and negative sputum specimen was submitted to clinical procedure until final diagnosis could be reached. $X$-rays showed abnormal shadws in 558 people. One thousand three hundred and seventy-nine people were found to have respiratory symptoms. A total 90 active cases were found; 57 of these were bacillary and 33, abacillary (5 of them asymptomatic). Of the 30,846 persons screened by $X$-ray, $230(0.75 \%)$ were found to be radiologically abnormal, and $5.6 \%$, that is, 5 out of 90 , active cases. That 5 remaining, clinically inimportant, asymptomatic and abacillary cases would have been missed. A mathematical estimate of the potential danger of this type of case suggests that it is irrelevant to the well-being of a community.

UNITERMS: Tuberculosis. Tuberculosis, pulmonary. Sputum, bacteriologic tests. Fluoroscopy.

\section{REFERENCIAS BIBLIOGRAFICAS}

1. ARANTES, G. R. Contribuigão para a integragāo das atividades anti-tuberculose nas unidates sanitárias do Estado de São Paulo. São Paulo, 1972. [Dissertação de Mestrado - Faculdade de Saúde Pública da USP].

2. ARANTES, G. R. Aplicação de modelo matemático visando à escolha da melhor combinação de instrumentos para a descoberta e tratamento de casos de tuberculose pulmonar. Rev. Saúde públ., S. Paulo, 12:455-70, 1978.

3. ARANTES, G. R. Racionalização do uso da abreugrafia nos programas de luta anti-tuberculose. Rev. Div. nac. Preumol. sanit., 23(89/90):35-41, 1979.

4. BAAS, M, A. Applied survelllance of diagnostic and treatment measures. Bull. int. Un. Tuberc., 55:281-6, 1976.

5. BANERJI, D. \& ANDERSEN, S. A sociological study of awareness of symptoms among persons with pulmonary tuberculosis. Bull. Org. Mond. Santé, $29: 665-83,1963$.

6. GIKOVATE, F. \& NOGUEIRA, D. P. Abreugrafia sistemática em massa: inviabilidade econômica e eventuais perigos da exposição a radiações. $R e v$. Saude públ., S. Paulo, 10:103-10, 1976.

7. MEIJER, J. et al, I lentification des sources d'infection. Bull. int. Un. Tuberc., $45: 5-54,1971$.

8. OLAKOWISKI, T. Assignement report on a tuberculosis longitudinal survey, $\mathrm{Na}$ tional Tuberculosis Institute, Bangalore, WHO project: India 0103. New Delhi, WHO. Regional Office for South East Asia, 1973. (SEA/TB/129).

9. PAMRA, S. P. Case-finding. Bull. int. Un. Tubero., 47(Suppl., 2):131-6, 1972.

10. PAMRA, S. P. \& MATHUR, G. P. Effects of chemoprofilaxis on minimal pulmonary lesions of doubtful activity. Bull. Wld Hlth Org., 45:593-602, 1971. 
ARANTES, G. R. \& RUFFINO-NETTO, A. Busca de casos de tuberculose pulmonar: abreugrafia em sintomáticos respiratórios, seguida de exames bacteriológicos nos suspeitos. Rev. Sande públ., S. Paulo, 14:185-93, 1980.

11. RUFFINO-NETTO, A \& ARANTES, G. R. Risco de infecção tuberculosa $\mathrm{\epsilon m} \mathrm{mu}-$ nicípio do interior do Estado de São Paulo e suas aplicacões. Rev. Saúde públ., S. Paulo, 10:143-9, 1976.

12. SCOTTISH THORACIC SOCIETY, Research Committee. A controlled trial of chemotherapy in pulmonary tuberculosis of doubtful activity: five year follow-up. Tubercle, Lonton, 14:39-46. 1963.

13. SODHY, J. S. Case-finding. Bull. int. Un. Tuberc., 47 (Suppl., 2):119-29, 1972.

14. SPRINGETT, V. H. \& ELEY, A. J. Minimal tuberculosis found by mass ra- diography (fluorography). A report to the Prophit Committee. London, H. K. Lewis, 1956.

15. STYBLO, K. Epidemiologia de la tuberculosis. Bol. Un. int. Tuberc., 53:145-57, 1978.

16. STYBLO, K. \& SUTHERLAND, I. Epidemiological indices for planning surveillance and evaluation of tuberculosis programms. Bull. int. Un. Tuberc., 49:66-73, 1974.

Recebido para publicaşa em $06 / 11 / 1979$ A provado para publicasâa em 21/02/1980 
ARANTES, G. R. \& RUFFINO-NETTO, A. Busca de casos de tuberculose pulmonar: abreugrafia em sintomáticos respiratórios, seguida de exames bacteriológicos nos suspeitos. Rev. Saúde públ., S. Paulo, 14:185-93, 1980.

ANEXO

IRRELEVANCIA EPIDEMIOLOGICA DOS CASOS ASSINTOMATICOS

Convencionemos que:

$y=$ percentagem de deterioração (evolução para doença bacilifera) desses casos;

$\mathrm{x}=$ tempo em anos, no qual ocorrerá a deterioração de y de casos.

No trabalho citado (Pamra e Mathur ${ }^{10}$, 1971), constam os valores para $\mathrm{x}=1, \mathrm{y}=$ $13 \%$ e para $x=6, y=32 \%$; e outros dados que permitiram fossem inferidos os pares de valores intermediários, a saber: para $x$ $=2, y=20 \%$; para $\mathrm{x}=3, \mathrm{y}=26 \%$; para $\mathrm{x}=4, \mathrm{y}=28 \%$ e para $\mathrm{x}=5, \mathrm{y}=$ $31 \%$.

Esses valores dificilmente traduziriam uma relação linear entre $y$ e $x$, por sinal pouco freqüente em fenômenos biológicos; colocados em gráfico, e assim analisados, foi possivel obter um ajustamento satisfatório da função do tipo $y=b$. $x^{k}$, com os seguintes valores dos parâmetros:

$b=13,03$ e $k=0,55$, ou seia:

$$
y=13,03 x^{0,55}
$$

conhecendo-se o número de casos que se deterioraram (ou a percentagem y), é possivel calcular o número esperado (z) de pessoas que se infectarão a partir dessas novas fontes, o qual será dado por:

$$
z=\frac{\text { c. n. } y}{100}
$$

onde, $z=$ números de novos infectados

$\mathrm{n}=$ número de assintomáticos com lesões radiológicas

$c=$ parâmetro de contágio * (número de pessoas infectadas por uma fonte bacilifera, não tratada no decorrer de 1 ano).

$\mathrm{Na}$ Tabela e na Figura são apresentadas as percentagens esperadas de deterioração (y) em função do tempo (x); essa Tabela apresenta ainda o número esperado de novos infectados (z) a partir das fontes baciliferas recém-geradas.

A utilização da fórmula (1) implica que se tenham em mente algumas ressalvas:

a) a função foi ajustada com apenas 6 pares de valores e de uma única fonte (Pamra e Mathur 10, 1971); embora sujeita a restrições, a função mostra uma tendênciã que não é descabida em epidemiologia;

b) y será sempre uma superestimação do número real de casos deteriorados uma vez que, nos 40,7 anos teoricamente necessários para a ocorrência de todas as deterioraçōes possiveis, alguns desses casos sofreriam remissão espontânea ao passo que outros teriam falecido, inclusive de outras causas.

Isto posto, observa-se que o número de novos infectados $(z)$, ainda que superestimado, é irrisório, não só no ano $\mathrm{x}$ como no total acumulado até 0 ano $x$.

Com o que se pode afirmar que o seu potencial epidemiológico é desprezivel.

\footnotetext{
* Estimado para a cidade de Ribeirão Preto como sendo igual a 8 (Ruffino-Netto e Arantes 11, 1976); Styblo 15 (1978) assinala o valor médio de 10 pessoas.
} 
ARANTES, G. R. \& RUFFINO-NETTO, A. Busca de casos de tuberculose pulmonar: abreugrafia em sintomáticos respiratórios, seguida de exames bacteriológicos nos suspeitos. Rev. Saúde públ., S. Paulo, $14: 185-93,1980$.

\section{T A B E L A}

Número esperado de infectados, decorrente da deterioração bacilifera de casos assintomáticos de tuberculose pulmonar não tratada, em função do tempo.

\begin{tabular}{|c|c|c|c|}
\hline \multirow{2}{*}{$\begin{array}{l}\text { Tempo (X) } \\
\text { em anos }\end{array}$} & \multirow{2}{*}{$\begin{array}{c}\text { Taxa de } \\
\text { deterioração }(y)^{*}\end{array}$} & \multicolumn{2}{|c|}{$\begin{array}{l}\text { Número esperado de novos } \\
\text { infectados }(Z)^{* *} \text {. }\end{array}$} \\
\hline & & No ano $\mathrm{X}$ & Até 0 ano $x$ \\
\hline 1 & 13,03 & $1,0424 \mathrm{n}$ & $1,0424 n$ \\
\hline 2 & 19,07 & $1,5256 \mathrm{n}$ & $2,5680 \mathrm{n}$ \\
\hline 3 & 23,84 & $1,9072 n$ & $4,4752 n$ \\
\hline 4 & 27,99 & $2,2392 n$ & $6,7144 \mathrm{n}$ \\
\hline 5 & 31,57 & $2,5256 \mathrm{n}$ & $9,2400 \mathrm{n}$ \\
\hline 6 & 34,90 & $2,7920 n$ & $12,0320 \mathrm{n}$ \\
\hline 7 & 37,99 & $3,0392 \mathrm{n}$ & $15,0712 \mathrm{n}$ \\
\hline 8 & 40,89 & $3,2712 \mathrm{n}$ & $18,3424 \mathrm{n}$ \\
\hline 9 & 43,62 & $3,4896 \mathrm{n}$ & $21,8320 \mathrm{n}$ \\
\hline 10 & 46,23 & $3,6984 n$ & $25,5304 \mathfrak{n}$ \\
\hline 15 & 57,78 & $4,6224 \mathrm{n}$ & $30,1528 \mathrm{n}$ \\
\hline 20 & 67,68 & $5,4144 \mathrm{n}$ & $35,5672 \mathrm{n}$ \\
\hline 30 & 84,59 & $6,7672 \mathrm{n}$ & $42,3344 \mathrm{n}$ \\
\hline 40 & 99,10 & $7,9280 \mathrm{n}$ & $50,2624 \mathrm{n}$ \\
\hline 40.7 & 100,00 & $10,0000 \mathrm{n}$ & $60,2624 \mathrm{n}$ \\
\hline
\end{tabular}

$y=13,03 \times 0,55$

** $Z=\frac{8 \mathrm{ny}}{100}$

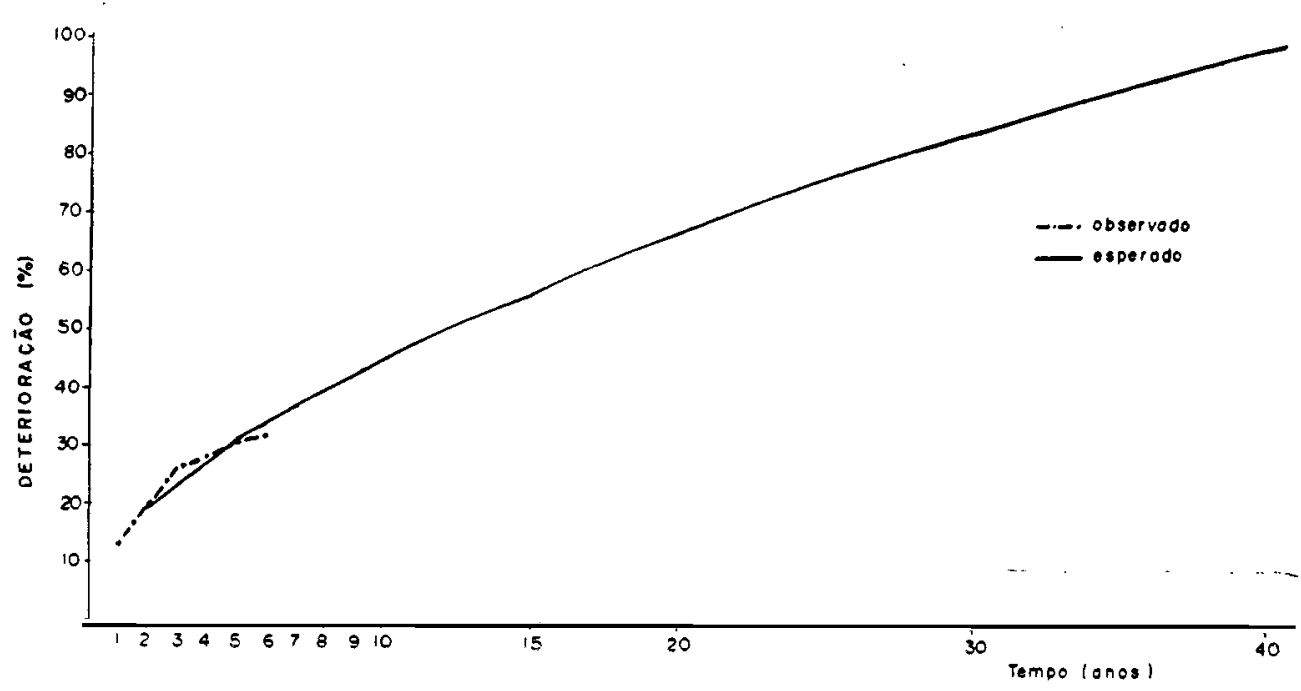

Figura - Taxa de deterioração dos "casos" assintomáticos em funçăo do tempo. 